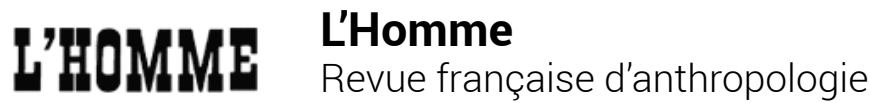

231-232| 2019

Cumulus : Hoarding, Hosting, Hospitality

\section{Sandra Bornand, ed., Noces en paroles chez les Zarma (Niger)}

\section{Cécile Leguy}

\section{(2) OpenEdition \\ 1 Journals}

\section{Édition électronique}

URL : https://journals.openedition.org//homme/35888

DOI : 10.4000/lhomme.35888

ISSN : 1953-8103

Éditeur

Éditions de l'EHESS

\section{Édition imprimée}

Date de publication : 21 novembre 2019

Pagination : $317-320$

ISBN : 978-2-7132-2794-3

ISSN : 0439-4216

Référence électronique

Cécile Leguy, « Sandra Bornand, ed., Noces en paroles chez les Zarma (Niger) », L'Homme [En ligne], 231-232 | 2019, mis en ligne le 21 novembre 2019, consulté le 23 avril 2022. URL : http:// journals.openedition.org//homme/35888; DOI : https://doi.org/10.4000//homme.35888

Ce document a été généré automatiquement le 23 avril 2022.

(c) École des hautes études en sciences sociales 


\title{
Sandra Bornand, ed., Noces en paroles chez les Zarma (Niger)
}

\author{
Cécile Leguy
}

\section{RÉFÉRENCE}

Sandra Bornand, ed., Noces en paroles chez les Zarma (Niger). Paris, Classiques africains, 2018, 412 p., bibl. (« Classiques africains » 36).

1 Sandra Bornand nous invite, dans cet ouvrage, à prendre de la hauteur afin d'assister à un mariage polygame en pays zarma en ayant une vision d'ensemble des différents épisodes qui le composent. L'événement est ainsi reconstitué de façon à être témoin de chaque partie du rituel selon qu'elle concerne la mariée, le marié, la coépouse qui perd son statut de dernière épousée, ou encore ceux qui règlent ces épisodes en l'absence des futurs époux... ce que nul convive ne pourrait vivre en réalité. Intégrée depuis ses premières enquêtes sur les griots généalogistes ${ }^{1}$ dans une famille nigérienne, l'auteure a participé à de nombreux mariages, au cours desquels elle a été amenée à jouer différents rôles: des rôles familiaux en tant que sœur ou mère classificatoire d'un garçon ou d'une fille de sa famille d'adoption; un rôle social en accompagnant le griot lors d'unions célébrées dans de grandes familles de l'aristocratie zarma; et même le rôle privilégié de protagoniste de son propre mariage au Niger, en tant que fille de sa famille d'adoption.

2 Il ne s'agit cependant pas d'une simple relation ethnographique. Publié dans cette collection des «Classiques africains» centrée sur les productions littéraires orales, l'ouvrage se présente comme une expérience ethnopoétique, les paroles enregistrées et retranscrites étant le support de l'ensemble du rituel qu'elles rythment et auquel elles donnent sens. Sept tableaux se suivent et nous entraînent de la veillée jusqu'à la nuit de noces, qui vient clore le temps du mariage.

3 Le premier de ces tableaux réunit des chants émis lors de la veillée chez la fiancée. Durant toute la soirée, la future épouse reste enfermée dans sa chambre, tandis que la 
cour familiale, bondée de monde, résonne des voix de cinq griottes. Ce temps festif qui précède la cérémonie religieuse est destiné aux femmes mariées, plus précisément à toutes celles qui sont en position de "mère " par rapport à la jeune femme. $Y$ assistent également des jeunes filles et des garçons célibataires, pour lesquels cela peut être une occasion de rencontres. Les chants alternent les parties en solo et les reprises par le chœur ou par une autre griotte. Ils incitent aux dons en invitant les femmes à être dignes de leurs prestigieux ancêtres, tout en suscitant les danses : les mères se lèvent pour danser quand on les interpelle et terminent leur performance en collant un billet sur le front en sueur de la chanteuse. L'ensemble se doit d'être réussi dans la mesure où le succès de cette soirée est censé augurer la bonne marche du mariage lui-même. Du côté du marié, dans l'exemple présenté et comme c'est souvent le cas aujourd'hui, la soirée se passe plus simplement, entre jeunes hommes, à fêter l'événement autour d'un bon repas et avec des musiques d'ambiance.

Cet épisode, qui marque le début du rituel de mariage, est aussi assez symptomatique de ce qui se joue lors des unions dans cette société islamisée : argent et autres richesses y circulent en nombre. Le coût d'un mariage est en effet assez impressionnant. La compensation matrimoniale elle-même, bien qu'officiellement limitée à 50000 Francs CFA (environ 75 euros), peut en réalité représenter plusieurs milliers d'euros quand on prend en compte tous les présents faits avant le mariage, en espèce ou en argent, par le futur époux : dès ses premières visites de courtoisie dans la maison de sa promise, des billets sont glissés sous une natte, des cadeaux sont donnés - pagnes, sucre, argent pour se coiffer - à la jeune fille comme à sa famille. Le mariage semble être une véritable transaction financière, aspect renforcé aujourd'hui, lors de l'établissement des fiançailles, par une délégation menée par un des oncles paternels du prétendant, du fait $\mathrm{du}$ remplacement des anciens dons de bétail et d'esclaves par de grosses sommes d'argent.

5 Le lendemain de la veillée se déroule la cérémonie religieuse, qui est une affaire d'hommes à laquelle aucun des futurs époux n'assiste. Les hommes de la famille du marié, accompagnés de leur(s) griot(s), se rendent en cortège chez le père de la fiancée, où ils sont reçus, dans la cour, par des hommes de la famille, des voisins, des amis, d'autres griots et des joueurs de tambour d'aisselle, pendant que les femmes attendent à l'intérieur la fin de cette cérémonie. En plus des paroles religieuses et des bénédictions, cet épisode du rituel comprend des appels d'ancêtres et des éloges adressés aux membres des deux familles et aux notables présents, comme ici celui destiné à la sœur d'un chef de canton, femme plantureuse louée là encore pour sa générosité envers les griots, manière pour eux d'inviter chacun à ne pas être avare en ce jour de fête.

6 Puis, dans le troisième tableau, l'auteure nous présente l'événement tel qu'il est vécu du côté du marié et de ses proches. Durant la cérémonie, le jeune marié se réfugie chez son meilleur ami, qui assure pendant ce temps la réussite de la fête de mariage, en prenant en charge l'animation, notamment le repas pour tous les invités. L'ambiance est particulièrement festive, mais le jeune marié reste reclus dans la maison de son confident pendant que ses sœurs et ses amis dansent et mangent. Deux types de griots peuvent être présents : des joueurs de tambour d'aisselle qui adressent des éloges au garçon et à ses proches, et des griots généalogistes qui énoncent des appels d'ancêtres, mais aussi des épopées ou des récits. Sandra Bornand restitue dans ce chapitre l'un de ces éloges, où se mêlent appels métaphoriques à la générosité des aristocrates loués et 
éléments de critique sociale. Elle reproduit également un long récit épique en l'honneur d'Issa Korombé, héros local du XIXe siècle, tout en en comblant les ellipses, dues à la connivence entre le griot et la famille du jeune homme, avec des extraits d'une version enregistrée dans d'autres circonstances.

7 Le quatrième tableau décrit ce qui se passe parallèlement du côté de la mariée. L'événement a été vécu et relaté par Sandra Bornand elle-même, en tant que première concernée. Sa famille d'adoption lui a en effet proposé d'organiser son propre mariage "à la manière d'autrefois ", ce qui impliquait que son futur mari, suisse comme elle, soit pour l'occasion adopté par une famille alliée. C'est donc cachée sous une couverture, comme toute future épousée, après avoir été lavée au henné, qu'elle a pu entendre par bribes la conversation destinée à faire son éducation sexuelle, menée par des femmes feignant d'ignorer sa présence. Puis, elle a entendu de loin des femmes mariées chanter dans la cour pour préparer les plus jeunes à leur future vie d'épouse ; dans leurs chants, elles se plaignent de leur sort, présentant la vie dans une bellefamille comme un enfer et celle passée dans sa famille de naissance sous le signe de la liberté. Ensuite, ses sœurs et amies célibataires sont venues dans sa chambre chanter leurs espoirs et leurs craintes vis-à-vis de leur futur mariage, au rythme du pilon utilisé par les «mères" de la mariée pour confectionner l'encens. Parmi ces chants, ceux reproduits dans l'ouvrage avaient été recueillis à l'occasion d'autres mariages, quelques mois auparavant, dans de meilleures conditions d'enregistrement pour l'ethnologue.

Durant cet épisode, on comprend que les mères chantent pour mettre en garde la future mariée et lui signaler ses droits, notamment celui de quitter le foyer conjugal si elle n'est pas satisfaite du traitement qu'elle y reçoit. Dans ces chants de séparation, les paroles sont vouées à faire pleurer celles et ceux qui les entendent, en premier lieu la mariée elle-même... Elles s'adressent aussi à ses cadettes, averties de la sorte de toutes les peines pouvant s'abattre sur une fille partie se marier loin de sa famille. L'encens pilé est offert à un génie protecteur dans l'intention de communiquer avec lui. Ainsi invoqué avant que la promise soit conduite à son mari, ce génie peut se manifester par la bouche d'une femme qui se met alors à hurler, comme ce fut le cas lors de la performance du chant intitulé "Ajoute l'encens à l'encens!», enregistré pendant le mariage de l'auteure (pp. 242-245). Cet épisode est suivi d'une toilette elle aussi accompagnée d'un chant, lors de laquelle la future mariée apprend à nettoyer ses parties génitales afin d'être pure pour la rencontre qui se prépare.

9 Le temps de la conduite vers la chambre nuptiale est présenté du côté de la mariée d'abord, puis de celui du marié. Sandra Bornand mentionne, en décrivant des faits et paroles enregistrés lors d'un mariage en 2012, les nombreux changements qui ont eu lieu ces dernières années concernant ce moment du mariage, liés à la place prise par l'islam mais aussi à l'amélioration des conditions de vie induite par la modernisation de la société zarma. Par exemple, le fait que la future mariée soit conduite en voiture a eu pour conséquence de supprimer les chants que les tantes entonnaient quand elles se tenaient aux côtés de la jeune fille portée à dos d'homme ou de jument... La mariée reste cependant bien cachée sous sa couverture, attendant qu'on l'emmène dans la chambre nuptiale précédemment bénie par un marabout.

Quant au marié, il est également lavé et parfumé. Il reçoit, avec un grigri protecteur, des conseils d'aînés qu'il devra suivre pour honorer son épouse dès la première nuit ; puis il est, à son tour, conduit à la chambre nuptiale sous une couverture portée en dais. Assis près de sa future femme, il doit à nouveau payer pour qu'elle découvre son 
visage et qu'elle accepte de lui parler. C'est à ce moment que, dans les familles prestigieuses, les griots généalogistes viennent proclamer des appels d'ancêtres et raconter des récits. En mettant en rivalité les membres des familles présentes dans la chambre, chacun est invité, encore une fois, à se montrer généreux. Le récit de distraction donné en exemple, souvent énoncé par Djibo Badjé, dit Djéliba («le grand griot »), lors de mariages polygames, a été enregistré en février 2001. Pleine d'humour, cette histoire met en parallèle la beauté intérieure d'une première épouse, fille de chef au cœur noble, et la superficielle beauté extérieure d'une rivale, invitant les hommes à réfléchir sur les qualités féminines à privilégier chez une épouse, avant de se laisser séduire par la seule apparence.

11 Les mariages polygames entraînent bien souvent des tensions, ce dont tiennent compte les Zarma en permettant qu'un marcanda, un événement festif en l'honneur de celle qui perd son statut de dernière épousée, soit organisé juste avant la nuit de noces. L'ouvrage se termine donc sur le cas des femmes dont le mari prend une nouvelle épouse. La soirée consiste principalement en échanges de joutes verbales d'insultes, rythmées comme des battles de rap, entre des femmes épousées en premières noces, à l'exception de l'intéressée, et des femmes épousées en seconde. Ces insultes rituelles mettent en scène, par des paroles renvoyant parfois très explicitement au plaisir sexuel quand elles sont émises par des griottes ou des descendantes de captives, la rivalité que s'apprêtent à vivre les deux protagonistes. Ces paroles particulièrement crues, échangées sur un mode conflictuel au départ, aboutissent à une sorte d'accord censé préparer les co-épouses à vivre ensemble et à s'allier contre leur mari commun.

Présenter cet ouvrage comme un recueil de textes «édités par " Sandra Bornand ne rend pas justice à l'immense travail de l'auteure qui, non seulement nous donne accès à un ensemble diversifié de chants, éloges, récits en zarma avec une traduction française de grande qualité, mais nous invite aussi au cœur de la performance, entendue au sens de Richard Bauman ${ }^{2}$ comme événement et action. Car c'est bien le pouvoir de ces paroles sur l'union matrimoniale qui est en jeu ici, dans ses dimensions propitiatoires et performatives.

\section{NOTES}

1. Cf. Sandra Bornand, Le Discours du griot généalogiste chez les Zarma du Niger, Paris, Karthala, 2005 ( Tradition orale »).

2. Cf. Richard Bauman, Verbal Art as Performance, New York, Waveland Press, 1977. 